УДК 634.8:631.524.01/.7:631.526.32/.542.3

(470.75)

DOI 10.30679/2219-5335-2019-3-57-60-71

ОЦЕНКА ПОТЕНЦИАЛА АБОРИГЕННЫХ И МЕСТНЫХ СОРТОВ ВИНОГРАДА ДЛЯ УПРАВЛЕНИЯ ПРОЦЕССОМ ФОРМИРОВАНИЯ УРОЖАЯ*

Бейбулатов Магомедсайгит Расулович д-р с.-х. наук

начальник отдела агротехники

Урденко Наталия Александровна

канд. с.-х. наук

ст. научный сотрудник

отдела агротехники

Тихомирова Надежда Александровна

канд. с.-х. наук

ст. научный сотрудник

отдела агротехники

Буйвал Роман Алексеевич

канд. с.-х. наук

научный сотрудник

отдела агротехники

Федеральное государственное бюджетное учреждение науки «Всероссийский начиональный научноисследовательский институт виноградарства и виноделия «Maгapaч» $P A H »$, Ялта, Республика Крым, Россия

Целью данной работы является Оценка потенциальной плодоносности, определение максимальной зоны значений коэффициента плодоношения, проведение регрессионного анализа зависимости закладки зачатков соцветий от размещения глазков по длине лозы аборигенных и местных сортов винограда в условиях
UDC 634.8:631.524.01/.7:631.526.32/.542.3 (470.75)

DOI 10.30679/2219-5335-2019-3-57-60-71

\section{CAPACITY ASSESSMENT OF ABORIGINAL AND LOCAL GRAPEVINE CULTIVARS FOR MANAGING HARVEST FORMATION PROCESS}

Beybulatov Magomedsaigit Rasulovich Dr. Sci. Agr.

Head of Agrotechnology Department

Urdenko Natalia Alexandrovna

Cand. Agr. Sci.

Senior Research Associate

of Agrotechnology Department

Tikhomirova Nadezhda Aleksandrovna Cand. Agr. Sci.

Senior Research Associate of Agrotechnology Department

Buival Roman Alekseyevich

Cand. Agr. Sci.

Research Associate of Agrotechnology Department

Federal State Budget

Scientific Institution

All-Russian National

Research Institute

of Viticulture and Winemaking

«Magarach of RAS»,

Yalta, Republic of Crimea, Russia

The aim of this work is to assess the potential fruitfulness, determine the maximum zone of the values of the coefficient of fruiting, to carried out a regression analysis of the dependence of the inflorescences buds on the placement of buds along the length of the vine of indigenous and local grapes

\footnotetext{
* Работа выполняется в рамках Государственного задания Минобрнауки Российской Федерации (№ 0833-2015-0013).
} 
Черноморского региона Крыма для дальнейшего определения нагрузки на куст и длины обрезки плодовых лоз. Исследования проводились по общепринятым методикам и методическим разработкам по виноградарству. В горно-долинном приморском районе Черноморской агроэкологической зоны Южнобережного Крыма определена зона максимальных значений коэффициента плодоношения растений винограда - с 7 по 10 глазок по длине побега. Изучаемые сорта винограда Кокур белый и Сары Пандас, по результатам исследования, имеют очень высокие значения коэффициента плодоношения, соответственно 1,67 и 1,74; сорт Кефесия низкий коэффициент плодоношения $(0,5)$; сорт Эким Кара - высокий $(0,96)$, столовый сорт Асма - средний $(0,82)$. Установлена тесная корреляционная связь между эмбриональной плодоносностью центральных почек и порядковым номером глазков по длине лозы растений винограда. На основании обобщения результатов исследований оптимизирован регламент длины обрезки плодовых лоз, что должно обеспечить увеличение производства виноградной продукции. Выделена наиболее продуктивная зона по длине плодовых лоз как потенциал будущей урожайности. Указано, что должны быть приняты направленные на качество технологические решения: районирование сортов с учётом подбора почвенноклиматических условий произрастания, агротехнология сорта, начиная с определения потенциальной плодоносности, направленная на стабильность потенциала сортов винограда с учётом специализации использования сырья.

Ключевые слова: ВИНОГРАД, АБОРИГЕННЫЕ СОРТА, МЕСТНЫЕ СОРТА, СОРТОВАЯ АГРОТЕХНИКА, КОЭФФИЦИЕНТ ПЛОДОНОШЕНИЯ, УРОЖАЙНОСТЬ in the Black Sea region of Crimea to further determine the bush's load and the pruning length of fruit vines. The study were carried out according to generally accepted methods and methodological developments in viticulture. In the Mountain-Valley Seaside Region of the Black Sea agroecological zone of the South Coast Crimea, the zone of maximum values of the coefficient of fruiting of grape plants is defined from 7 to 10 buds along the length of the shoot. The studied grape varieties of Kokur White and Sary Pandas, according to the results of the study, of very high values of the fruiting coefficient, respectively 1.67 and 1.74; Kefesia variety of low coefficient (0.5); Ekim Kara - high ones (0.96), Asma table medium ones (0.82). A close correlation was established between the embryonic fruitfulness of the central buds and the ordinal number of the ocelli along the length of the grape vine. Based on a summary of research results, the regulation of the pruning length of fruit vines has been optimized, which will ensure an increase in the production of grape products. The most productive zone along the length of fruit vines was selected as a potential for future yield. It is indicated that technological solutions should be made to quality: regionalization of varieties taking into account the selection of soil and climatic growing conditions, agricultural technology of the varieties, starting with the determination of potential fruitfulness, aimed at the potential stability of grape varieties taking into account the specialization of the use of raw materials.

Key words: GRAPES, INDIGENOUS VARIETIES, LOCAL VARIETIES, VARIETY'S AGROTECHNOLOGY, FRUITFULNESS RATIO, YIELD 
Введение. Приоритетной задачей развития российской винодельческой отрасли является ориентирование производителей на выпуск высококачественной и конкурентоспособной продукции, в том числе с географическим статусом, отличительные качественные признаки которой определяются характерными для географического объекта их производства природными и антропогенными факторами $[1,2]$. В современной конкурентной среде сортимент винограда, а следовательно, ассортимент винопродукции формируется исходя из специализации предприятия, экономических интересов и конъюнктуры потребительского рынка [3].

Аборигенные и местные сорта винограда прошли проверку на совместимость с Крымским терруаром. Потенциал этих сортов огромен для виноградовинодельческой отрасли Крыма. В погоне за классическими европейскими сортами и модой, аборигенные и местные сорта винограда за последние пятьдесят лет ушли на второй план.

Сегодня при современных технологиях возделывания интерес к аборигенным и местным сортам у производственников существенно возрос. Их цель получить урожай, а следовательно, конкурентоспособную уникальную винодельческую продукцию и свежий виноград, которые обладали бы индивидуальными качествами, характеризующими их терруар [4].

Площадь виноградников в Республике Крым на 01.01.2018 г. составила 18,22 тыс. га, из них технических сортов - 16,08 тыс. га и столовых 2,12 тыс. га, в том числе плодоносящих - 15,7 тыс. га [5]. В одном из крупнейших виноградарских объединений Республики Крыма ФГУП «ПАО «Массандра» с общей площадью плодоносящих виноградников 3449,73 га сосредоточены следующие аборигенные и местные сорта винограда: Сары Пандас - 2,54 га, Кокур белый - 592,34 га, Эким Кара и Кефесия - 17,46 га, Асма - 37,40 га, из них вырабатывается винодельческая продукция сухого и десертного направления с защищенным географическим указанием (ЗГУ) и с защищенным наименованием места происхождения (КНМП). 
Плодоводство и виноградарство Юга России № 57(03), 2019 г.

Производство вин этой категории должно основываться на ряде технологических решений: использование потенциала сортов винограда для получения высококачественного и стабильного урожая - сырья для виноделия. Поэтому исследования эмбриональной плодоносности винограда и определение потенциальной урожайности сорта позволяют прогнозировать будущий урожай, что актуально.

Многочисленными исследователями установлено, что характер закладки соцветий в центральных почках зимующих глазков у сортов винограда во многом зависит от почвенно-климатических условий, срока созревания сорта, его генетических особенностей [2, 4, 6-12].

Предварительный детальный анализ почвенно-климатических и геоморфологических условий является первостепенным условием оптимизации размещения виноградных плантаций [6]. Данное исследование приобретает особо важное практическое значение при подборе сортимента винограда, определения формы кустов, расчета нагрузки кустов глазками, установлении оптимальной длины обрезки плодовых лоз, отзывчивости сорта на проведение агротехнических мероприятий для получения урожая хорошего качества в конкретных условиях.

Для последующей закладки маточников аборигенными и местными сортами винограда в Черноморском регионе Крыма необходимо оценить их потенциал, что ляжет в основу разработки и усовершенствования технологии их выращивания. Это значительно расширит и увеличит потенциал ассортимента продукции.

В связи с этим, целью работы является оценка потенциальной плодоносности, определение максимальной зоны значений коэффициента плодоношения, проведение регрессионного анализа зависимости закладки зачатков соцветий от размещения глазков по длине лозы аборигенных и местных сортов винограда в условиях Черноморского региона Крыма, для дальнейшего определения нагрузки на куст и длины обрезки плодовых лоз. 
Объекты и методы исследований. В течение 2017-2018 гг. сотрудниками лаборатории агротехнологий винограда ФГБКН ВННИИВиВ «Магарач» $\mathrm{PAН»} \mathrm{проводились} \mathrm{исследования} \mathrm{по} \mathrm{определению} \mathrm{потенциала} \mathrm{або-}$ ригенных и местных сортов винограда Крыма: Сары Пандас, Кокур белый, Эким кара, Кефесия, Асма (1985-1988 годов посадки).

Опытные участки расположены в горно-долинном районе Южнобережной зоны Крыма на производственных массивах ФГУП «ПАО «Массандра», филиалы: «Малореченское», «Морское», «Судак». Вариант представлен 45 кустами. Схема посадки кустов 3,0x1,5 м. Форма куста - двусторонний кордон на среднем штамбе.

Исследования проводились по общепринятым методикам и методическим разработкам по виноградарству $[13,14]$.

Анализ метеорологических условий местности в годы проведения исследований проводили по данным метеостанции г. Феодосии в сравнении со средними многолетними данными.

Плодоносность почек определяли путём микроскопирования каждого зимующего глазка по 10 типичным лозам каждого сорта (микроскопом МБС-10) перед началом обрезки виноградных кустов. Все показатели изучали до 10-го (включительно) глазка. Плодоносность побега оценивали по шкале: 1,2 и выше - очень высокая; 1,1-0,9 - высокая; 0,8-0,6 - средняя; 0,5-0,3 - низкая; 0,2 и ниже - очень низкая.

Учёт урожая в годы исследований проводили в сроки накопления требуемой для выработки десертных виноматериалов массовой концентрации сахаров в ягодах (в период с 10 сентября по 30 октября), покустно путем взвешивания. Математическую обработку полученных экспериментальных данных проводили методами математической статистики (корреляционный анализ) с использованием ПК, при помощи пакетов статистической программы Statistika 10.0, а также пакета анализа данных электронной таблицы Excel. 
Плодоводство и виноградарство Юга России № 57(03), 2019 г.

Обсуждение результатов. Виноградарство в наибольшей степени зависит от почвенно-климатических условий зоны возделывания. Поэтому необходимо учитывать влияние почвенно-климатических условий при размещении сортов и их возделывании.

В горно-долинном приморском районе Южнобережной зоны Крыма за период 2017-2018 гг. среднегодовая температура воздуха составила: $+13,5{ }^{\circ} \mathrm{C}, 14,0{ }^{\circ} \mathrm{C}$ (среднемноголетнее значение $14,8{ }^{\circ} \mathrm{C}$ ). Сумма активных температур ( $\geq 10{ }^{\circ} \mathrm{C}$ ) составляет $3910,5{ }^{\circ} \mathrm{C}, 4383,2{ }^{\circ} \mathrm{C}$ (среднемноголетнее значение $3911,2{ }^{\circ} \mathrm{C}$ ). Осадков выпало 296,9 мм и 584,1 мм (среднемноголетнее значение 459,1 мм) [15]. Таким образом, наблюдается повышение в 2017-2018 гг. среднемесячной температуры воздуха, отсюда и суммы активных температур на $235,7^{\circ} \mathrm{C}$.

Вышесказанное подтверждает факт повышения среднегодовой температуры и высокую тепло-, влагообеспеченность горно-долинного приморского района Южнобережной зоны Крыма, что необходимо учитывать при подборе сортимента винограда и ориентироваться на аборигенные сорта, прошедшие многолетнюю адаптацию к почвенно-климатическим условиям местности возделывания.

Эффективностью формирования желаемых технологических параметров винограда является научное обоснование районирования сортов винограда $[16,17,18]$ и направленности использования сырья, а также агротехнология, соответствующая сорту и местности произрастания.

Одним из первых этапов для разработки и усовершенствования элементов сортовой агротехнологии является анализ эмбриональной плодоносности почек зимующих глазков, в целях определения потенциальной урожайности, а также максимальных значений закладки коэффициента плодоношения по длине лозы и в дальнейшем определения оптимальной длины обрезки плодовых лоз по сортам винограда (табл. 1). 
Таблица 1 - Плодоносность почек аборигенных и местных сортов винограда и её характеристика, в среднем под урожай 2017-2019 гг.

\begin{tabular}{|c|c|c|c|c|}
\hline Сорт & $\begin{array}{c}\text { Минимальное } \\
\text { значение К } 1 \\
\text { (номер глазка) }\end{array}$ & $\begin{array}{c}\text { Максимальное } \\
\text { значение К } \\
\text { (номер глазка) }\end{array}$ & $\begin{array}{c}\text { Среднее } \\
\text { значения К } 1 \\
\text { по длине лозы }\end{array}$ & $\begin{array}{c}\text { Урожайность, } \\
\text { Т/га } \\
\text { (2017-2018 г.) }\end{array}$ \\
\hline \multicolumn{5}{|c|}{ Автохтонные сорта винограда } \\
\hline Кокур белый & $0,5(1)$ & $1,94(7)$ & 1,67 & 5,0 \\
\hline Сары Пандас & $0,8(1)$ & $2,05(9)$ & 1,74 & 5,9 \\
\hline Кефесия & $0,2(0-2)$ & $0,79(10)$ & 0,5 & 7,2 \\
\hline Эким Кара & $0,0-0,4(0-1)$ & $1,35(9)$ & 0,96 & 4,4 \\
\hline Асма & $0,5(0-2)$ & $1,30(8)$ & 0,82 & 7,6 \\
\hline
\end{tabular}

Из табл. 1 видно, что у представленных аборигенных и местных сортов винограда минимальные значения коэффициента плодоношения глазков $\left(\mathrm{K}_{1}\right)$ располагаются в зоне углового, первого и второго глазков. В условиях горно-долинного приморского района Южнобережной зоны Крыма зона максимальных значений коэффициента плодоношения у аборигенных и местных сортов винограда находится в зоне с 7 по 10 глазок.

Исследуемые сорта Крыма Кокур белый и Сары Пандас имеют очень высокие значения среднего коэффициента плодоношения, соответственно 1,67 и 1,74. Сорт Кефесия имеет низкий коэффициент плодоношения глазков $\left(\kappa_{1}=0,5\right)$, сорт Эким Кара - высокий $\left(\kappa_{1} 0,96\right)$ и сорт Асма - средний $\left(K_{1} 0,82\right)[14,19]$. При этом аборигенные и местные сорта винограда имеют низкие и средние значения средней массы грозди, что формирует низкие и средние значения урожайности. Это обусловлено большим возрастом кустов и сложившимися погодными условиями 2017-2018 гг.

Наряду с почвенно-климатическими условиями произрастания сортов винограда при закладке зачатков соцветий и формировании урожая важны сортовые особенности и агротехнология возделываемого сорта. На рис. 1, 2 и в табл. 2 показаны зависимости эмбриональной плодоносности центральных почек от порядкового номера глазков по длине лозы, что имеет практическое применение в виноградарстве для установления нагрузки на куст глазками и определения длины обрезки плодовых лоз. 


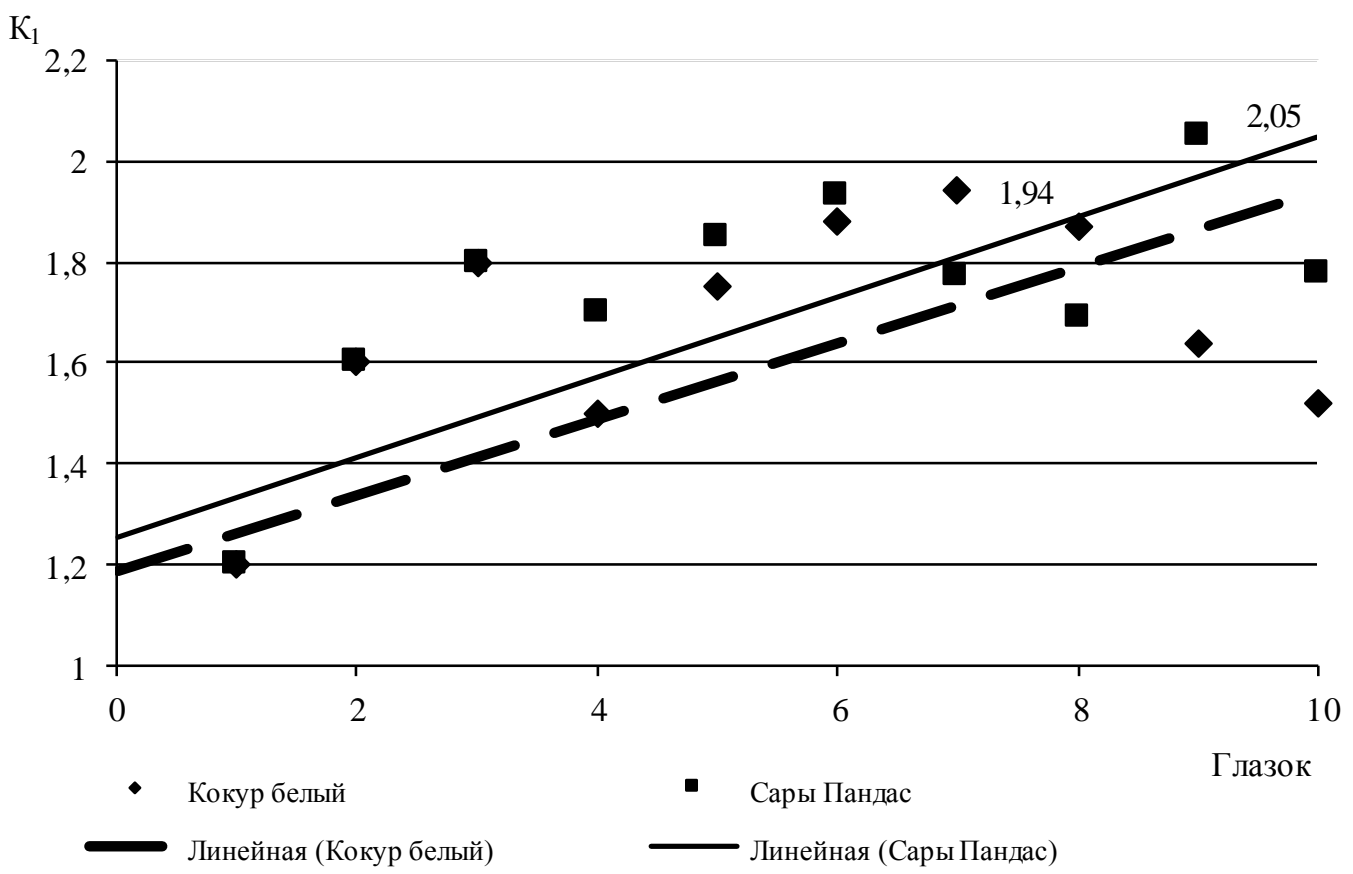

Рис. 1. Зависимость эмбриональной плодоносности центральных почек от порядкового номера глазков по длине лозы, белоягодные автохтонные сорта, горно-долинный приморский район Южнобережной зоны Крыма, 2019 г.

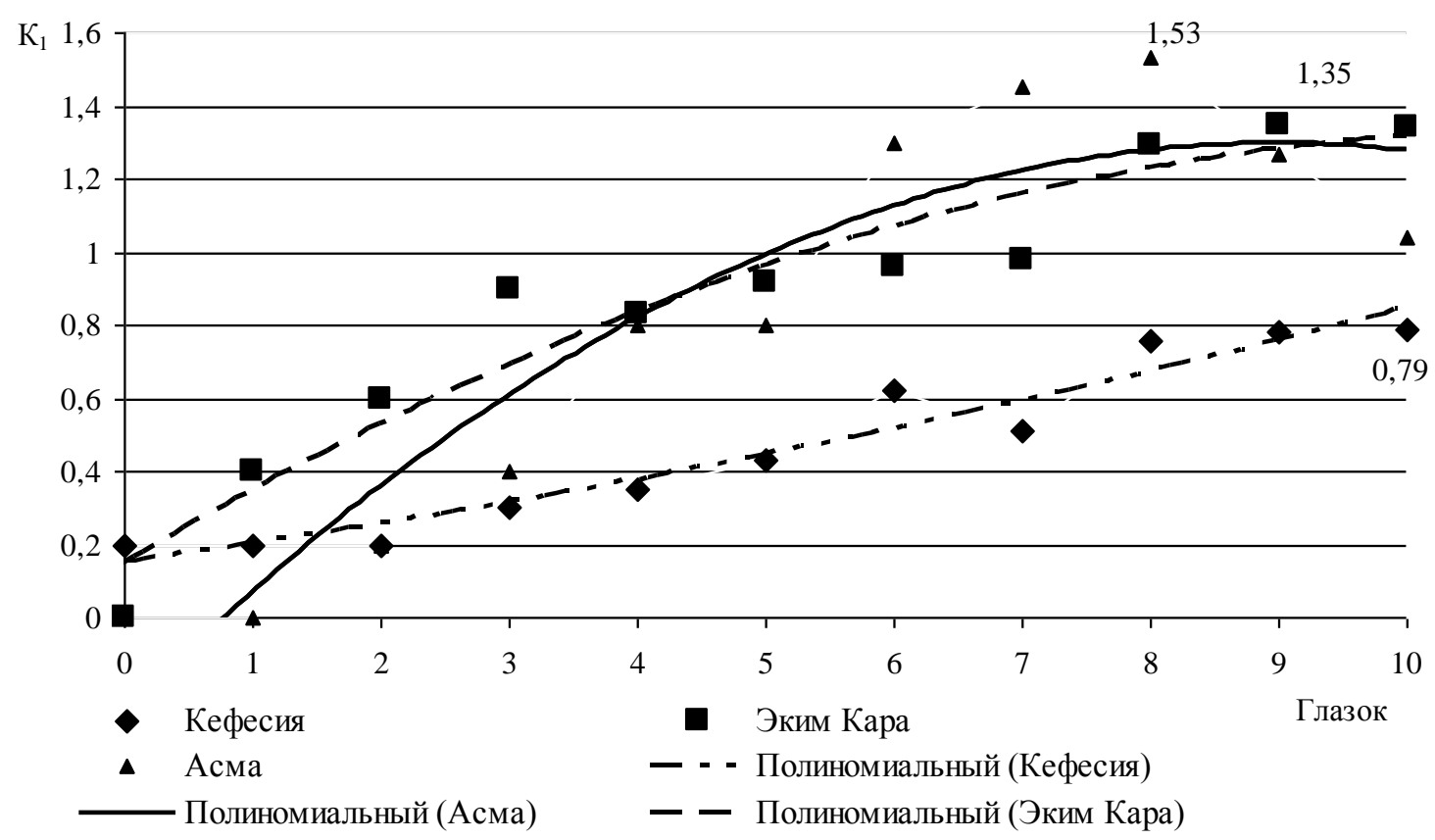

Рис. 2. Зависимость эмбриональной плодоносности центральных почек от порядкового номера глазков по длине лозы, темно ягодные автохтонные сорта, горно-долинный приморский район Южнобережной зоны Крыма, 2019 г. 
Плодоводство и виноградарство Юга России № 57(03), 2019 г.

Корреляционная связь между эмбриональной плодоносностью центральных почек и порядковым номером глазков по длине лозы описана уравнениями регрессии (см. табл. 2) и оказалась сильной практически у всех исследуемых сортов винограда, при этом коэффициент корреляции находился в пределах от 0,741 до 0,968, за исключением сорта Кокур белый.

Таблица 2 - Взаимосвязь между эмбриональной плодоносностью центральных почек и порядковым номером зимующих глазков по длине лозы сортов винограда, под урожай 2017-2019 гг.

\begin{tabular}{|l|c|c|c|}
\hline \multicolumn{1}{|c|}{ Сорт } & $\begin{array}{c}\text { Коэффициент } \\
\text { корреляции, } \mathrm{r}, \\
\text { (корреляционная } \\
\text { зависимость) }\end{array}$ & $\begin{array}{c}\text { Коэффициент } \\
\text { детерминации } \\
\left(\mathrm{R}^{2}\right)\end{array}$ & Уравнение регрессии \\
\hline \multicolumn{3}{|c|}{ Аборигенные сорта винограда } \\
\hline Кокур белый & 0,608 (средняя) & 0,370 & $\mathrm{y}=0,0757 \mathrm{x}+1,185$ \\
\hline Сары Пандас & 0,741 (сильная) & 0,549 & $\mathrm{y}=0,0795 \mathrm{x}+1,2545$ \\
\hline Кефесия & 0,968 (сильная) & 0,937 & $\mathrm{y}=0,0022 \mathrm{x}^{2}+0,0475 \mathrm{x}+0,1529$ \\
\hline Эким Кара & 0,962 (сильная) & 0,925 & $\mathrm{y}=-0,0092 \mathrm{x}^{2}+0,2088 \mathrm{x}+0,1477$ \\
\hline Асма & 0,940 (сильная) & 0,884 & $\mathrm{y}=-0,0192 \mathrm{x}^{2}+0,3458 \mathrm{x}-0,2564$ \\
\hline
\end{tabular}

Примечание: у - К 1 (коэффициент плодоношения), X - порядковый номер зимующих глазков по длине лозы винограда

Bbыводы. На основании регрессионного анализа и обобщения результатов экспериментальных исследований оценен потенциал плодоносности аборигенных и местных сортов винограда в условиях Крыма. Определено, что корреляционная зависимость между эмбриональной плодоносностью центральных почек зимующих глазков и порядковым номером по длине лозы у сортов винограда выражается прямолинейной корреляционной связью у всех технических аборигенных и местных сортов, а у столового аборигенного сорта винограда Асма - корреляционная связь обратная. Количество урожая в будущем зависит от характера эмбриональной плодоносности центральных почек глазков по длине лозы.

Таким образом, в основе производства вин с географическим статусом, отображающих терруар и конкурентоспособность отрасли, должны быть применены направленные на качество технологические решения: 
Плодоводство и виноградарство Юга России № 57(03), 2019 г.

районирование сортов с учетом подбора почвенно-климатических условий произрастания, разработанная агротехнология сорта, начиная с определения потенциальной плодоносности, направленная на стабильность потенциала сортов винограда по специализации использования сырья.

На основании регрессионного анализа и обобщения результатов экспериментальных исследований оценен потенциал сортов винограда, установлены закономерности закладки эмбриональных соцветий и оптимизирован регламент длины обрезки плодовых лоз, что обеспечит увеличение производства виноградной продукции. Выделена наиболее продуктивная зона по длине плодовых лоз для изучаемых сортов винограда как потенциал будущей урожайности.

Авторы выражают благодарности: главному агроному ФГУП «ПАО «Массандра» Поляковой Т.Н., агроному филиала «Морское» ФГУП «ПАО «Массандра» Валишину П.А. - сбор материала.

Участие авторов: Урденко Н.А. - анализ полученных данных, написание текста, Бейбулатов М.Р. - концепция исследования, Тихомирова Н.А. и Буйвал Р.А. - сбор и обработка материалов.

\section{Литература}

1. Российская Федерация. Законы. О государственном регулировании производства и отбора этилового спирта, алкогольной и спиртосодержащей продукции и об ограничении потребления (распития) алкогольной продукции: Федер. закон: [принят Гос. Думой 19 июля 1995 г.: одобр. Советом Федерации 15 ноября 1995 г.]. М.: Проспект, 2016. 80 с. (Актуальный закон). ISBN 5392208614.

2.Jackson, D.I. Environmental and Management practices affecting Grape composition and wine Quality - a Review / D.I. Jackson, P.B. Lombard // Am. J. Enol., Vitic., 1993. Vol. №4. 22 p.

3. Дергунов А.В., Перов Н.Н. Оптимизация технологических и агроэкологических параметров производства высококачественной продукции // Организационноэкономический механизм инновационного процесса и приоритетные проблемы научного обеспечения развития отрасли: материалы науч.-практ. конф. (3-4 февр. 2003 г.). Краснодар: СКЗНИИСиВ, 2003. С. 487-495.

4. Seguin, G. «Terroirs» and pedology of vine growing // Experienta. - 1986. № 42. P. 861-873.

5. Рюмшин А.В., Иванченко В.И., Булава А.Н. Состояние и перспективы развития виноградно-винодельческого комплекса Республики Крым // «Магарач». Виноградарство и виноделие. 2018. № 3. С. 44-47. 
6. Дикань А.П. Потенциальная плодоносность и урожай винограда. Симферополь, 1996. 135 с.

7. Оценка агробиологических и хозяйственных признаков клона сорта винограда Мускат белый VCR-3 в условиях Южного берега Крыма [Электронный ресурс] / М.Р. Бейбулатов, Р.А. Буйвал, Н.А. Тихомирова, Н.А. Урденко // Плодоводство и виноградарство Юга России. 2018. № 51(3). С. 89-99. URL: http://journalkubansad.ru/pdf/18/03/09.pdf. DOI: 10.30679/2219-5335-2018-3-51-89-99 (дата обращения: 04.04.2019).

8. Приоритеты в технологическом развитии промышленного винограда / Е.А. Егоров, В.С. Петров, Г.А. Шадрина, Г.А. Кочьян // Виноделие и виноградарство. 2018. № 3. C. 18-21.

9. Изучить агробиологические и хозяйственные признаки новых сортов и клонов винограда в условиях Крыма. ФГБУН «ВННИИВиВ «МАГАРАЧ» РАН»; рук. Бейбулатов М.Р.; отв. исп. Тихомирова Н.А., Урденко Н.А.; исп. Буйвал Р.А., Матюха Р.А., Мокрогуз Л.М. Ялта, 2016. 76 с., № АААА-А17-117011810045-5.

10. Стоев, К. Физиология винограда и основы его возделывания. Т 3. София: Изд-во Болгарской Академии наук, 1983. 382 с.

11. Sotes, V. The role of the Landscape as a component of the terroir in Spain (Do Bierzo) / V. Sotes, Gomez-Miguel // Paysages de vigneset de vins. Collogue International. Abbaye Royale de Fontevraud, 2-4 juillet, 2003. P. 239-242.

12. Morlat, R. Les relation entre le terroir, la vigne et le vin // Comptes Rendus de l'Academie dAgriculture de France. 1988. № 2. P. 19-2.

13. Доспехов, Б.А. Методика полевого опыта (с основами статистической обработки результатов исследований). М.: Колос, 1985. 377 с.

14. Методические рекомендации по агротехническим исследованиям в виноградарстве Украины / под ред. А.М. Авидзба. Ялта: ИВиВ «Магарач», 2004. 264 с.

15. Расписание погоды. URL: //rp5.ru/docs/search/ru.

16. Kadir Sorkel A. Vitis vinifera и V. aestivalis Growth of Vitis vinifera L. and Vitis aestivalis Michx. as affected by temperature 11 Int. J. Fruit. Sei. 2005. 5. № 3. c. 69-82.

17. Chuine, I. Historical phenology: Grape ripening as a past climate indicator / I. Chuine // Nature. 2004. V. 432. P. 289-290.

18. Colapietra, M. Valutazione agronomica e commerciale di 16 nuve cultivar di uve apurene / M. Colapietra, V. Catalane // L'Informatore Agrario. 1988. Vol. 44. № 27. P. 45-59.

19. Петров. В.С., Павлюкова Т.П., Талаш А.И. Научные основы устойчивого выращивания винограда в аномальных погодных условиях: монография / под ред. Петрова В.С. Краснодар: ГНУ СКЗНИИСиВ, 2014. 157 с.

20. Carboneau A. Evaluation of grapevine cultivars: ecophysiological adaption and wine quality / A. Carboneau // VI Intern. Symp. on Grape Breeding, Yalta, Ukraine. 1994. P.88-89.

\section{References}

1. Rossijskaya Federaciya. Zakony. O gosudarstvennom regulirovanii proizvodstva i otbora etilovogo spirta, alkogol'noj i spirtosoderzhashchej produkcii i ob ogranichenii potrebleniya (raspitiya) alkogol'noj produkcii: Feder. zakon: [prinyat Gos. Dumoj 19 iyulya 1995 g.: odobr. Sovetom Federacii 15 noyabrya 1995 g.]. M.: Prospekt, 2016. 80 s. (Aktual'nyj zakon). ISBN 5392208614.

2. Jackson, D.I. Environmental and Management practices affecting Grape composition and wine Quality - a Review / D.I. Jackson, P.B. Lom-bard // Am. J. Enol., Vitic., 1993. Vol. №4. 22 p. 
3. Dergunov A.V., Perov N.N. Optimizaciya tekhnologicheskih i agroekologicheskih parametrov proizvodstva vysokokachestvennoj produkcii // Organizacionno-ekonomicheskij mekhanizm innovacionnogo processa i prioritetnye problemy nauchnogo obespecheniya razvitiya otrasli: materialy nauch.-prakt. konf. (3-4 fevr. 2003 g.). Krasnodar: SKZNIISiV, 2003. S. 487-495.

4. Seguin, G. «Terroirs» and pedology of vine growing // Experienta. - 1986. № 42. P. 861-873.

5. Ryumshin A.V., Ivanchenko V.I., Bulava A.N. Sostoyanie i perspektivy razvitiya vinogradno-vinodel'cheskogo kompleksa Respubliki Krym // «Magarach». Vinogradarstvo i vinodelie. 2018. № 3. S. 44-47.

6. Dikan' A.P. Potencial'naya plodonosnost' i urozhaj vinograda. Simferopol', 1996. $135 \mathrm{~s}$.

7. Ocenka agrobiologicheskih i hozyajstvennyh priznakov klona sorta vinograda Muskat belyj VCR-3 v usloviyah Yuzhnogo berega Kryma [Elektronnyj resurs] / M.R. Bejbulatov, R.A. Bujval, N.A. Tihomirova, N.A. Urdenko // Plodovodstvo i vinogradarstvo Yuga Rossii. 2018. № 51(3). S. 89-99. URL: http://journalkubansad.ru/pdf/18/03/09.pdf. DOI: 10.30679/2219-5335-2018-3-51-89-99 (data obrashcheniya: 04.04.2019).

8. Prioritety v tekhnologicheskom razvitii promyshlennogo vinograda / E.A. Egorov, V.S. Petrov, G.A. Shadrina, G.A. Koch'yan // Vinodelie i vinogradarstvo. 2018. № 3. S. $18-21$.

9. Izuchit' agrobiologicheskie i hozyajstvennye priznaki novyh sortov i klonov vinograda v usloviyah Kryma. FGBUN «VNNIIViV «MAGARACh» RAN»; ruk. Bejbulatov M.R.; otv. isp. Tihomirova N.A., Urdenko N.A.; isp. Bujval R.A., Matyuha R.A., Mokroguz L.M. Yalta, 2016. 76 s., № AAAA-A17-117011810045-5.

10. Stoev, K. Fiziologiya vinograda i osnovy ego vozdelyvaniya. T 3. Sofiya: Izd-vo Bolgarskoj Akademii nauk, 1983. $382 \mathrm{s.}$

11. Sotes, V. The role of the Landscape as a component of the terroir in Spain (Do Bierzo) / V. Sotes, Gomez-Miguel // Paysages de vigneset de vins. Collogue International. Abbaye Royale de Fontevraud, 2-4 juillet, 2003. P. 239-242.

12. Morlat, R. Les relation entre le terroir, la vigne et le vin // Comptes Rendus de ll'Academie dAgriculture de France. 1988. № 2. P. 19-32.

13. Dospekhov, B.A. Metodika polevogo opyta (s osnovami statisticheskoj obrabotki rezul'tatov issledovanij). M.: Kolos, 1985. $377 \mathrm{~s}$.

14. Metodicheskie rekomendacii po agrotekhnicheskim issledovaniyam v vinogradarstve Ukrainy / pod red. A.M. Avidzba. Yalta: IViV «Magarach», 2004. 264 s.

15. Raspisanie pogody. URL: //rp5.ru/docs/search/ru.

16. Kadir Sorkel A. Vitis vinifera i V. aestivalis Growth of Vitis vinifera L. and Vitis aestivalis Michx. as affected by temperature 11 Int. J. Fruit. Sei. 2005. 5. № 3. s. 69-82.

17. Chuine, I. Historical phenology: Grape ripening as a past climate indicator / I. Chuine // Nature. 2004. V. 432. P. 289 - 290.

18. Colapietra, M. Valutazione agronomica e commerciale di 16 nuve cultivar di uve apurene / M. Colapietra, V. Catalane // Ll'Informatore Agrar-io. 1988. Vol. 44. № 27. P. 45-59.

19. Petrov. V.S., Pavlyukova T.P., Talash A.I. Nauchnye osnovy ustojchivogo vyrashchivaniya vinograda $\mathrm{V}$ anomal'nyh pogodnyh usloviyah: monografiya / pod red. Petrova V.S. Krasnodar: GNU SKZNIISiV, 2014. 157 s.

20. Carboneau A. Evaluation of grapevine cultivars: ecophysiological adaption and wine quality / A. Carboneau // VI Intern. Symp. on Grape Breeding, Yalta, Ukraine. 1994. P.88-89. 